\title{
Primary subcutaneous cyst hydatid of abdominal wall: a case report
}

\author{
Mehmet Gulmez, ${ }^{1}$ Aysun Simsek Celik, ${ }^{1}$ Sevcan Alkan, ${ }^{1}$ Bugu Usanma Koban, ${ }^{2}$ \\ Rumeysa Soyalan Onal, ${ }^{1}$ Mehmet Ali Uzun ${ }^{1}$ \\ ${ }^{1}$ Department of General Surgery, Haydarpasa Numune Training and Research Hospital, Istanbul, Turkey \\ ${ }^{2}$ Department of Family Medicine, Haydarpasa Numune Training and Research Hospital, Istanbul, Turkey
}

\begin{abstract}
Human body is an intermediate host for Echinococcus granulosus which is a cestode causing hydatid disease. The most common type is E. Granulosus. E. Granulosus most often affects the liver and the lung. Primary subcutaneous cyst hydatid without involving other organs is extremely rare. A 60-year-old Turkish woman came to our hospital with a growing mass in the left periumblical region of the abdominal wall. In the superficial tissue ultrasonography a cystic mass measuring $3 \times 2 \mathrm{~cm}$ was detected in the subcutaneous tissue of left periumblical region of the abdominal wall and it was doubtful for hydatid cyst. The patient had no history of surgery for a hydatid cyst in any other organ and the hydatid serology was negative. The cyst was surgically, and carefully excised. Macroscopic exploration suggested a hydatid cyst with its germinative membrane and the histopathological examination of the specimen was reported as a hydatid cyst. Hydatid cyst should be considered when a subcutaneous cytic mass is detected in a patient living in the region where the disease is endemic. The best treatment is complete removal of the cysts.
\end{abstract}

Keywords: Abdominal wall; cyst hydatid; subcutaneous.

$\mathrm{H}$ uman body is an intermediate host for Echinococcus granulosus which is a cestode causing hydatid disease. The regions such as North Africa, South America, Middle East and Europe are the endemic areas for the disease. E. granulosus most often affects the liver (70\%) and the lung (10-15\%). Primary subcutaneous cyst hydatid without involving other organs is extremely rare [1]. In our presentation we describe a patient who has a growing mass in the left periumblical region of the abdominal wall.

\section{CASE REPORT}

A 60-year-old Turkish woman came to our hospital with a growing mass in the left periumblical region of the abdominal wall. She had her mass for about six months. The mass was fluctuant, mobile and painful. The overlying skin was hyperemic. In the superficial tissue ultrasonography (US) a $3 \times 2 \mathrm{~cm}$ cystic mass was detected in the subcutaneous tissue of left periumblical region of the abdominal wall.

Received: July 16, 2014 Accepted: December 11, 2014 Online: September 25, 2015

Correspondence: Dr. Mehmet GULMEZ. Haydarpasa Numune Egitim ve Arastirma Hastanesi, Genel Cerrahi Klinigi, Istanbul, Turkey. 
The lesion had a smooth contour and an avascular wall. It was doubtful for hydatid cyst. The hydatid serology was negative. The patient had no history of surgery for a hydatid cyst in any other organ. Magnetic Resonance Imaging (MRI) and computed tomography $(\mathrm{CT})$ were performed to confirm the diagnosis of hydatid cyst and to demonstrate relationship of cyst to adjacent organs. There was no other organ involvement including liver or lung, and no additional cysts were observed on the abdominal, and thoracal MRI and CT (Figure 1).

During the operation the cyst was found in the subcutaneous tissue and hypertonic saline (3\% $\mathrm{NaCl}$ ) was injected into the cyst and after waiting for $10 \mathrm{~min}$, the cyst was surgically and carefully excised. Macroscopic exploration suggested a hydatid cyst with its germinative membrane (Figure 2). Histopathological examination of the specimen was reported as a hydatid cyst.

\section{DISCUSSION}

Hydatid disease in humans is caused by the larval form of parasites of the genus Echinococcus. The most common type is E. granulosus.

The embryo which is liberated in the duodenum, penetrates the wall of the small intestine and enters into portal circulation. The liver is the most frequent localization for embryos. Some embryos may pass through the liver and find their way into the organs such as lung, muscle, spleen, brain and bone.

In the literature, the incidence of subcutaneous hydatid cyst is $2 \%$ of all hydatid cysts [2]. Most of these subcutaneous cysts are secondary to hepatic or pulmonary cysts. The primary hydatid cyst is very rare. In our case, the hydatid cyst was located in the subcutaneous tissue without any other organ localization.

The clinical course and symptoms of hydatid disease are nonspecific, and related to the localization and size of the cyst. It usually presents as painless and non-inflammatory mass [3]. However, in our patient, the mass was painful and the overlying skin was hyperemic.

The differential diagnosis of the soft tissue masses includes abscess, sebaceous cyst and lipoma. The correct preoperative diagnosis of a subcutane-

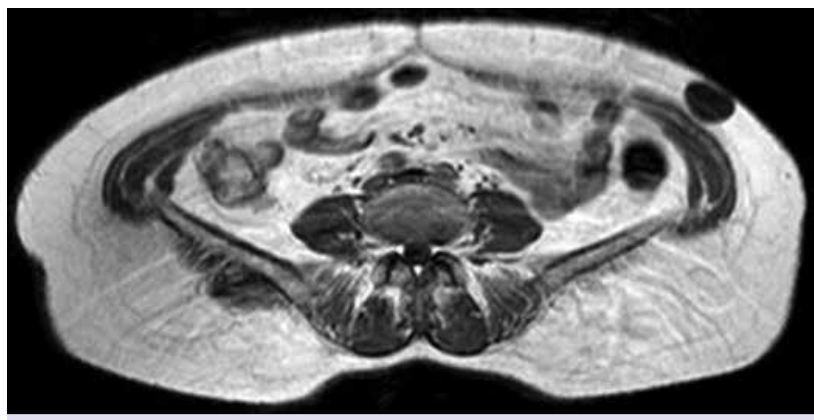

FIGURE 1. Subcutaneous hydatid cyst in the abdominal wall.

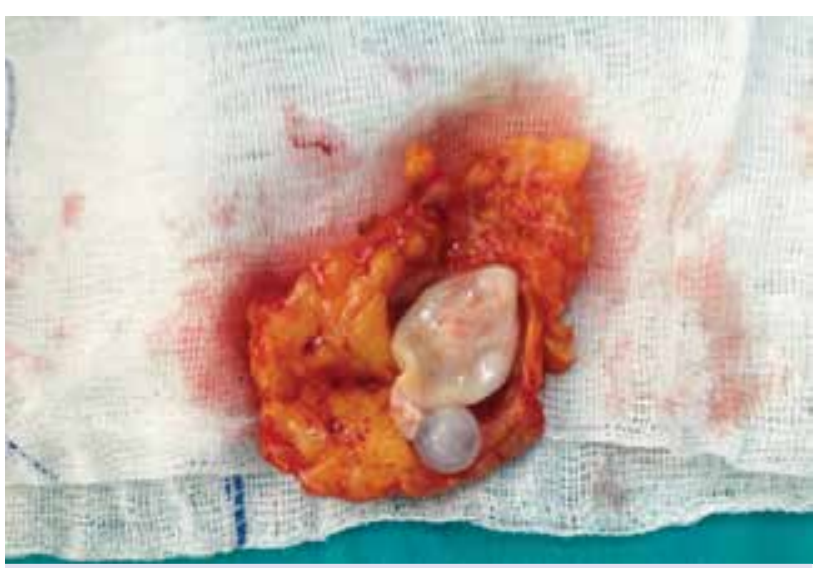

FIGURE 2. Hydatid cyst with its germinative membrane.

ous hydatid cyst is important because of the risks of anaphylaxis or recurrences due to spillage. $\mathrm{Ra}$ diological imaging modalities as US, CT and MRI are very useful for the diagnosis, determination of the size, type and localization of the cyst. We performed MRI and CT to confirm the diagnosis of hydatid cyst and to demonstrate relationship of cyst to adjacent organs. It is also helpful for the search of other organs. Daughter cysts, germinative membrane, calcification and thick cyst wall are specific radiological properties for hydatid cyst. Serological studies are the most reliable adjunct to imaging tests in confirming the diagnosis of echinococcosis. Although positive serological tests are helpful in the establishment of diagnosis, their absence does not exclude the presence of echinococcosis. They are rarely positive in extra-hepatic, and extra-pulmonary localizations [3]. In our patient the hydatid serology was negative.

Surgical removal of the cyst is the best treatment 
option for primary hydatid cyst. Surgeon must be careful not to perforate the cyst which can lead to anaphylaxis and local recurrence. If complete removal of the cyst is impossible, the cyst content including cyst fluid, daughter cysts, germinative membrane and protoscolices should be removed carefully. Scolicidal agents may be applied into the cavity at this time, which should be completely drained afterwards [4].

\section{Conclusion}

Hydatid cyst should be considered when a subcutaneous cytic mass is determined in a patient living in the region where the disease is endemic. Most of these subcutaneous cysts are secondary to hepatic or pulmonary hydatid cysts. Radiological examinations must be performed for the search of other organs such as liver and lung. The best treatment is the complete removal of the cysts.
Conflict of Interest: No conflict of interest was declared by the authors.

Financial Disclosure: The authors declared that this study has received no financial support.

\section{REFERENCES}

1. Kayaalp C. Hydatid cyst of the liver. In: Blumgart LH, Belghiti RJ, DeMatteo RP, Chapman WC, Büchler MW, Hann LE, D'Angleca M, editors. Surgery of liver biliary tract and pancreas. $4^{\text {th }}$ ed. Philadelphia: Saunders Elsevier; 2007. p. 952-70.

2. Chevalier X, Rhamouni A, Bretagne S, Martigny J, LargetPiet B. Hydatid cyst of the subcutaneous tissue without other involvement: MR imaging features. AJR Am J Roentgenol 1994;163:645-6.

3. Ousadden A, Elbouhaddouti H, Ibnmajdoub KH, Mazaz K, Aittaleb K. A solitary primary subcutaneous hydatid cyst in the abdominal wall of a 70-year-old woman: a case report. J Med Case Rep 2011;5:270.

4. Duncan GJ, Tooke SM. Echinococcus infestation of the biceps brachii. A case report. Clin Orthop Relat Res 1990;261:247-50. 